\title{
WEAR AND COEFFICIENT OF FRICTION OF PLA-GRAPHITE COMPOSITE IN 3D PRINTING TECHNOLOGY
}

\author{
W. Pawlak*
}

\begin{abstract}
Results of tribological research of influence of graphite on 3D printing filament are presented in this article. The research was conducted on the samples of composite of 50\% graphite and 50\% PLA printed then in FFF technology. As a sample on pin on disc research equipment there was used a cylinder of $8 \mathrm{~mm}$ diameter and $8 \mathrm{~mm}$ height. As a counterspecimen there was used a steel disc with Ra = (0.3-0.4).
\end{abstract}

Keywords: tribology, friction, wear, 3D printing, PLA

\section{Introduction}

3D printing technology is one of the most exciting technologies that are now breaking through to the regular people and one of those technologies which are now being strongly developed in new areas. Media shows that 3D printers are finding their way also to schools, kindergartens and even homes - and it is no coincidence, because of decreasing durability of everyday products, people are looking for ways to repair them at low cost. Over the last couple of years different printing technologies like FDM, FFF, SLA and SLS found their way mostly in prototyping industry. One of the biggest challenges is friction and wear of elements produced in the FFF (Fused Filament Fabrication) technology. Fig. 1. Shows the linear guideway with 3D-printed block. Next chapters of this article present another composite of the series polylactide-graphite composition. In the previous studies the compositions of 5, 10, 20 and 30\% samples were researched. After a series of promising result, there were manufactured samples of $50 \%$ graphite and $50 \%$ polylactide.

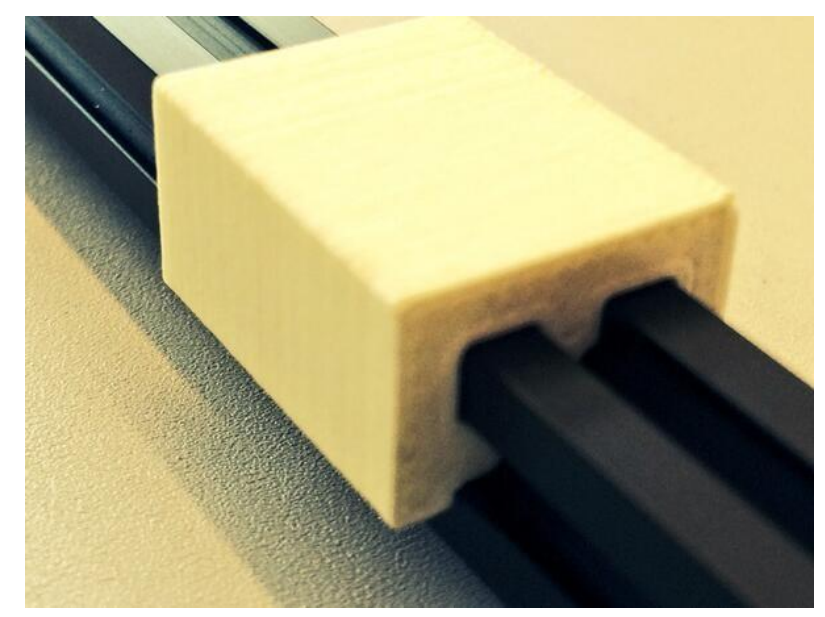

Fig. 1: Block of the linear guideway printed in FFF technology with Igus Iglidur material

Wojciech Pawlak.: Katedra Podstaw Konstrukcji Maszyn i Tribologii, Wrocław Univertsity of Science and Technology, Wyb. Stanisława Wyspiańskiego 27, 50-370 Wrocław, PL, w.pawlak@pwr.edu.pl 


\section{Research equipment}

As research equipment to conduct these experiments pin on disc tribometer was used. Scheme of the type of the experiment is shown in Fig. 2. and research equipment in Fig. 3. Machine was invented in $18^{\text {th }}$ century by Pieter van Musschenbroek. Tribometers usually occur in a version with a pin as a sample or a ball. Often used in reverse mode, where the pin or a ball is a counterspecimen. The results can be presented as linear wear of the pin, mass loss of the disc and coefficient of friction between two cooperating elements. As a sample in this research was used a pin of $8 \mathrm{~mm}$ diameter and $8 \mathrm{~mm}$ height created in FFF process of 3D printing technology. And as counterspecimen a steel disc, which roughness on the pin path was included in the range of $\mathrm{Ra}=(0.3-0.4)$. Linear wear was measured with micrometer screw gauge and friction force by force sensor attached to the tribometer's cover.

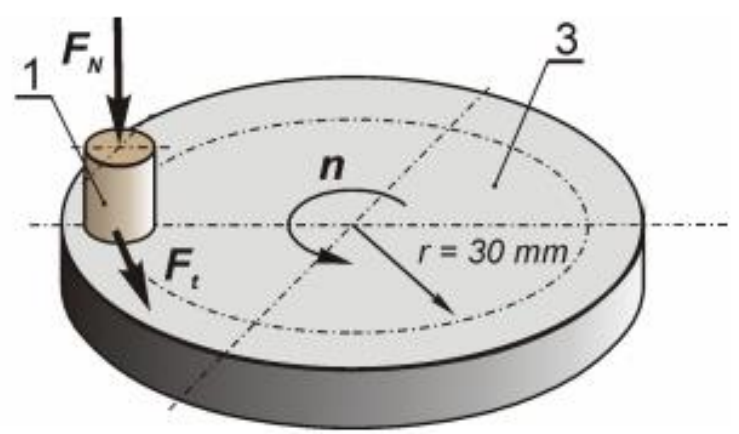

Fig. 2: Scheme of a sliding pair of the pin and disc (Capanidis and Wieleba, 2007)

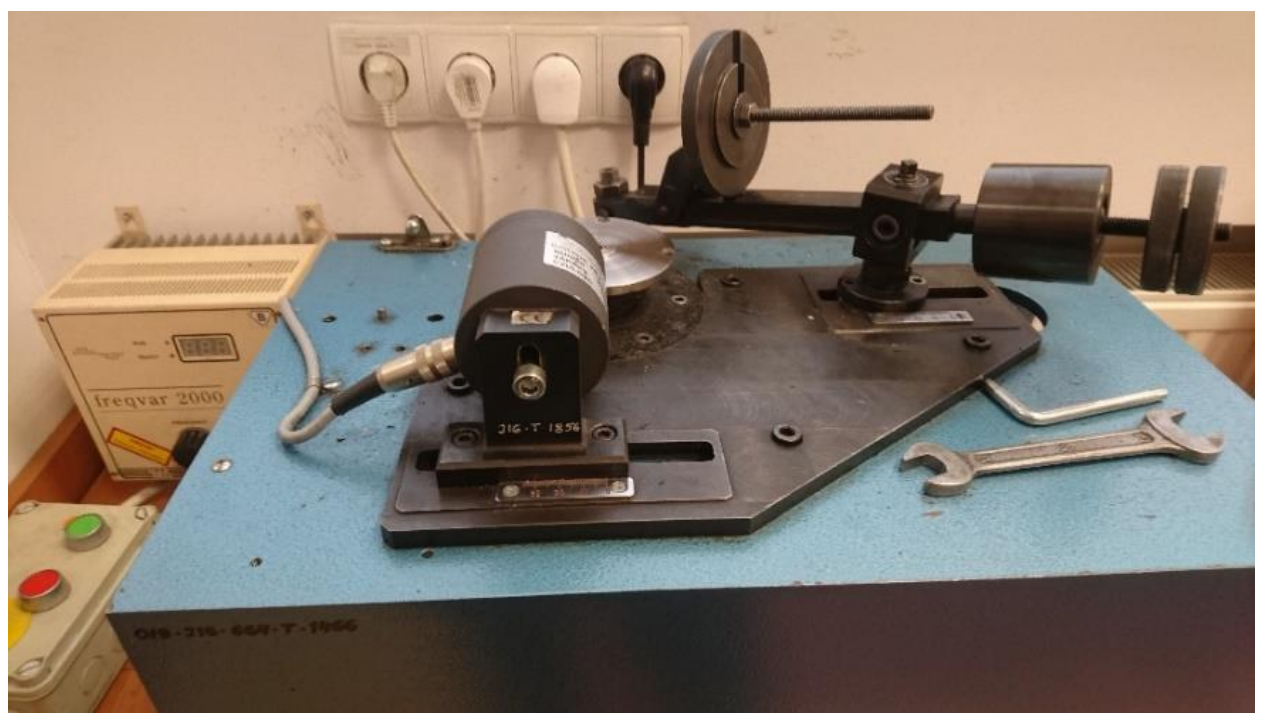

Fig. 3: Research equipment

\section{Research process}

In the course of research 3 separate samples of each material (Fig. 4.) were subjected to test. The parameters of tests and production process of pins are presented in Tab. 1. The most important parameter of production process was style of external layers. To provide isotropy of the sample it needs to be concentric (Fig. 5). 


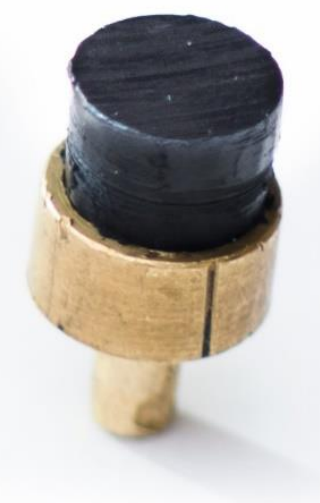

Fig. 4: Sample of PLA Graphite 50\%

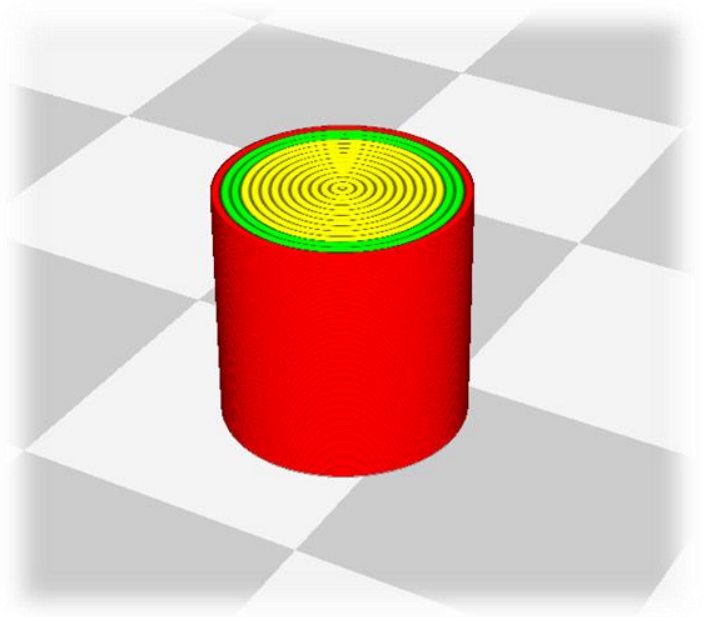

Fig. 5: Simulation of layers style in Cura software

Tab. 1: Parameters of the production process and tests

\begin{tabular}{|c|c|c|}
\hline & Parameter & Value \\
\hline \multirow{5}{*}{ Pin production process } & Infill percent of the sample & $20 \%$ \\
\hline & Extruder diameter & $0.3 \mathrm{~mm}$ \\
\hline & Layer height & $0.1 \mathrm{~mm}$ \\
\hline & Layer style & Concentric \\
\hline & Full layers up and bottom & 10 \\
\hline Disc parameters & Roughness & $\mathrm{Ra}=(0.3-0.4)$ \\
\hline \multirow{4}{*}{ Test's parameters } & Time of the single experiment & 2h $27 \mathrm{~min}$ \\
\hline & Load on the specimen & $5.49 \mathrm{~N}$ \\
\hline & Linear speed of the counterspecimen & $0.34 \mathrm{~m} / \mathrm{s}$ \\
\hline & Length of the experiment & $3 \mathrm{~km}$ \\
\hline
\end{tabular}

Before every test the counterspecimen was cleaned with alcohol and dry cloth to prevent degradation of the sample. All of the parameters were also calibrated between separate tests.

\section{Results}

In Fig. 6. there are presented results of the tests. Trend lines show difference in friction force, under the same conditions, for PLA Natural - without additives and PLA with 50\% of graphite. The course of the trend line shows, that the friction force does not change significantly over the whole duration of the test and oscillates around $1.5 \mathrm{~N}$ value, which results in 0.288 average value of coefficient of friction.

Tab. 2: Wear of samples of PLA Natural and PLA Graphite 50\%

\begin{tabular}{ccc}
\hline Sample & Wear value & Coefficient of friction \\
\hline PLA Natural & $15.2 \mu \mathrm{m} / \mathrm{km}$ & 0.492 \\
\hline PLA Graphite $50 \%$ & $3.73 \mu \mathrm{m} / \mathrm{km}$ & 0.288 \\
\hline
\end{tabular}




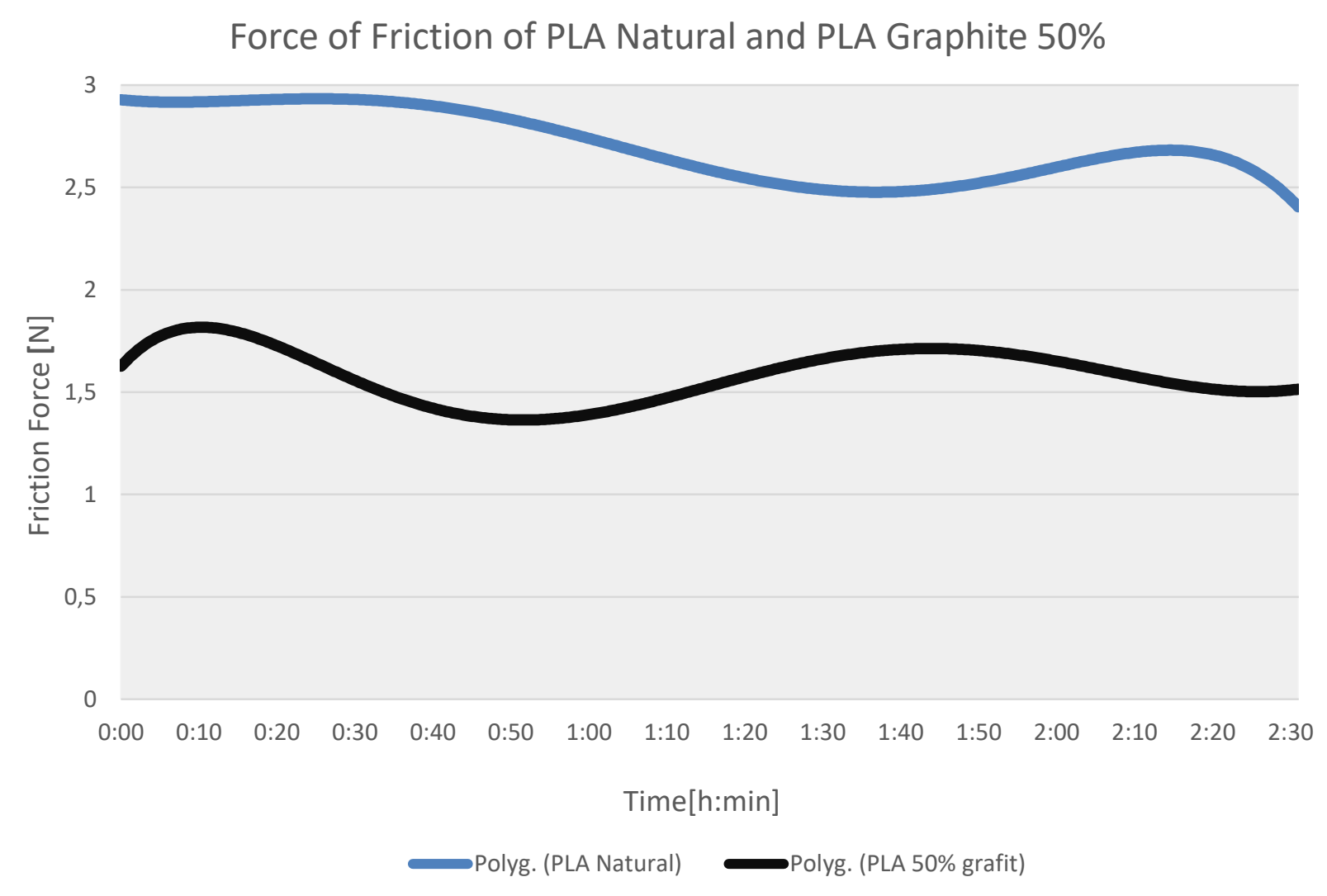

Fig. 6: Results described by trend lines of friction force for PLA Natural and PLA Graphite 50\%

\section{Conclusions}

Creating composite structure of $50 \%$ graphite and $50 \%$ polylactide allowed to decrease both coefficient of friction and linear wear. Previous research showed that optimal values of graphite addition in light of linear wear and coefficient of friction are 5\% and 50\% (Pawlak, et al., 2018). Between two options of PLA - graphite composite composition the 5\% is still more advisable due to easiness in 3D printing process. PLA Graphite 50\% is much more brittle, which caused difficulties during dosing the filament to the extruder. Another flaw is necessity of using direct extruder. Due to brittleness the filament can't bend on the feeder. Nevertheless research show, that adding a graphite to the PLA greatly improves its tribological properties. Next step will be creating a composition with $\mathrm{MoS}_{2}$ and PTFE.

\section{References}

Capanidis D. and Wieleba W. (2007) Research of friction of polymer composite materials, Laboratory instruction, Wrocław University of Science and Technology, Wrocław (Poland)

Pawlak W., Wieleba W., Kluczyński J., and Śnieżek L. (2018) Influence of graphite addition on tribological properties of polylactic (PLA) applied in 3D printing technology, Tribology 2018, Wrocław (Poland) 